(Originally printed as a NASPA Invited Paper, 1998. Reprinted by permission of The National Association of Student Personnel Administrators)

\title{
Steps to Creative Campus Collaboration
}

\author{
Jane Fried
}

\begin{abstract}
Orientation and transition professionals understand that change is multifaceted and complex. This paper outlines the steps to changing campus climate to include effective collaboration between academic and student affairs. Obstacles to dialogues, creating a common language, and "knowing in community" are discussed, and examples of programs easily lending themselves to collaborative efforts are given. Editor
\end{abstract}

Change always involves paradoxes. It is simultaneously frightening and exciting, attractive, and repellent. Changes in higher education provoke this paradoxical reaction among those of us who have devoted our lives to the management of colleges and universities and to the education of students. Paradoxical problems generate many conflicting explanations but no simple answers. Paradoxes are not questions-they are problematic situations which call for serious conversation. The notion of finding an "answer" may not serve well. The notion of increasing understanding and mapping out approaches to address the various elements of the paradox may serve much better. The issue of what to do about the flaws in our current system of higher education is based in our beliefs about the purposes of higher education. Which educational approaches best serve our society in this era? What values, skills, and knowledge do we want students to examine or learn in their college experience? What processes of teaching and learning will help us meet our goals and fulfill our values?

\section{Institutional Culture Presents Obstacles to Dialogue}

Finding answers to these questions may be difficult in the institutional culture that prevails throughout much of higher education today Parker Palmer (1998) describes it as a culture of fear in which people are:

- Separated from one another by status or by job,

- Separated from knowledge by an ideology of objectivity which makes personal knowledge less valuable than impersonal knowledge, and

- Separated from a sense of personal worth by constant ranking and competition for grades, publications, or resources.

We have an ingrained belief that if we "don't make the grade," our worth as human beings is diminished. Status in the ranking system can be changed by the loss of a grant, a bad grade, or a drop in group scores on outcome assessments. When performance and personal worth are synonymous, fear is pervasive. Nobody is secure. This makes

Jane Fried, Ph.D., is an Associate Professor at Central Connecticut State University and directs the master's program in Student Development in Higher Education. 
participation in serious, thought provoking, risk taking conversations a low-priority endeavor.

Teaching and learning as we have traditionally experienced them are part of this culture. If learning is about taking risks, how can people learn when they are constantly pressured to demonstrate how much they already know - either in the classroom or in the meeting room? The problem lies not so much in the people who teach and learn as in our common model of the teaching and learning process.

Student affairs professionals are continually involved in teaching students—or helping them learn-but our educational role is often invisible or misperceived through the lens of the dominant model. Esther Lloyd-Jones (Lloyd-Jones \& Smith, 1954) calls the work of student personnel the deeper teaching - teaching for character development, interpersonal competence and vocational choice and skill. Burns Crookston calls this work education for human development (1973), with a key dimension that he terms "affective rationality," or the integration of knowledge and feelings into a total learning process that takes facts, feelings, and meanings into account.

More recently, research in the cognitive sciences has demonstrated that "powerful learning is prompted when all five senses are engaged." We also know that emotional well being is essential to high level intellectual functioning. The mind-body-brain connection is dynamic at all times; each dimension of knowing interacts with the others (Marchese, 1998). Similar observations come from the ancient Chinese, whose proverb states, "Teachers open the door. You enter by yourself." and from Aristotle, who stated, "What we have to learn to do, we learn by doing." Whitehead (1929) and Dewey (1933) echoed these thoughts.

\section{We Can Create a Common Language}

In a culture that emphasizes separateness, how does a group begin to emphasize connections? In any cross-cultural encounter, participants must learn to speak a common language and understand one another's values, beliefs and culturally acceptable behavior. The gap between academic and student affairs professional cultures on most campuses is significant. The two groups have different understandings about the purposes of their work, the types of outcomes their work should produce and their accountability for measurable and immeasurable results. Student affairs professionals tend to work in groups or advise groups of students. Historically, faculty tend to work alone or in research groups. The rewards to which faculty typically aspire, such as tenure, promotion and publications, tend to accrue to individuals even when colleague groups or research assistants have been involved. In contrast, student affairs staffs tend to assume that group work is their normal mode. Program development and management tend to be accomplished by groups of people working within or across functional areas. Rewards often accrue to groups in the form of additional budget allocations or grants to develop programs or improve services.

Faculty members focus on framing and investigating problems and creating knowledge. Student affairs professionals, on the other hand, focus on applying knowledge and solving problems, particularly those related to management of student 
behavior and the physical, financial and programmatic elements of student life. Speed of response is far more important in student affairs than in academic affairs; problems are often high-profile. On the other hand, solutions to research problems appear in professional journals months to years after they are discovered. Many aspects of student affairs are of little concern to faculty, and the opposite is also true.

Student learning should be of profound interest to both groups, however. Although there may be serious disagreement about what students should learn or how learning should be organized, the creation of a common language to discuss learning is essential to effective collaboration. The common language must address issues such as these:

What do we consider academic learning, worthy of credit? Recent research has demonstrated that learning is not purely intellectual but involves behavioral skills and emotional capacities as well. "Our brain is a social brain," one group has written. "The search for meaning is innate; the brain establishes meaning through patterning; emotions are crucial to patterning; complex learning is enhanced by challenge, inhibited by threat" (Caine \& Caine, 1997).

What topics are appropriate for classroom discussion? How do we draw the line between "teaching" and "counseling" when a course addresses topics of personal concern to students and possibly to the instructor as well?

What is the teacher's role in a classroom: To present information? To control student behavior? To motivate students? Many choose to teach in colleges precisely because they do not want to be forced to motivate students or control their behavior, as do their colleagues in elementary and secondary schools. Yet behavior and motivation, particularly among college-age students, cannot be separated from learning. How can student affairs professionals, who often are responsible for minimizing negative student behavior or helping students develop motivation to succeed, work with faculty to share these responsibilities and support each other as well as their students?

How can out-of-class learning be designed and evaluated to ensure "rigorous" evaluation criteria? This is a very important question for faculty. Academics are required to evaluate student learning. Student affairs professionals have powerful assessment tools at their disposal such as focus groups, observation of behavioral change among groups of students, use of "reflection" devices in freshman orientation, service learning, and leadership seminars, to name just a few programs, as well as surveys and individual interviews. Powerful assessment tools used by student affairs professionals can also be applied to the curriculum in order to develop a common language and mutual respect between faculty and student affairs staffs.

What do we know about the ways people learn? Information about learning styles and cognitive development is widely available in the student affairs literature (Baxter Magolda, 1992; Perry 1970; and Belenky, Clinchy, Goldberger \& Tarule, 1986) and in learning style inventories. Graduates of many student affairs programs are familiar with this literature and with student learning in practical settings. By engaging our respective areas of professional knowledge, student affairs staff and faculty become genuine colleagues, bringing what we know to bear on problems of mutual concern. 


\section{We Can Focus on "Knowing the Community"}

In a culture that emphasizes the acquisition of static knowledge, how do we focus on dynamic interactions among learners, teachers, and knowledge? With a common language and set of understandings about learning as our base, we can begin to explore this question. Parker Palmer (1998) calls this "knowing in community," a frequent process in student affairs. Several persons engage in a conversation in which they try to understand an issue they care about. Palmer describes teaching as creating "a space in which the community of truth is practiced...(where) truth is an eternal conversation about things that matter, conducted with passion and discipline."

The dialogue proposed in this paper may be difficult to initiate and carry on. Any cross-cultural encounter is uncomfortable, unfamiliar and disorienting. These encounters often highlight internal contradictions in the lives of all participants that they would probably rather ignore. Yet all sides have a compelling interest in learning more about the issues raised earlier: What is the role of U.S. higher education in preparing students for work in a global economy? What skills do students need in order to solve problems effectively, think critically, and function well as team managers and players? What technological skills do they need, and what ethical frameworks will help them make beneficial decisions about the use of technology? What other dimensions of ethical belief and behavior are important to discuss as part of a college education? What skills, knowledge and wisdom do we want to impart to our students about participation in public affairs, not only government or voting, but local activism and community service? Do we care if students care about the conditions of the poor and disadvantaged in our society, where access to opportunity is increasingly a function of access to higher education and skills developed or not developed in third grade can affect the quality of a person's entire life? These topics are addressed in detail by the Wingspread Group's paper An American Imperative: Higher Expectations for Higher Education (1993). Individual campuses must decide which of these issues is of particular interest and what means might best be used to address them.

As we discuss and redefine student learning, we probably will find ourselves re-examining fundamental assumptions about higher education. Our discussions will challenge our beliefs about our roles, the value of attending college, ourselves and our skills as professionals and our status in the system. Our thinking about teaching, learning and evaluating may change. We all will certainly need to learn new skills.

\section{Many Program Areas Hold Promise for Collaboration}

This paper takes the position that most meaningful and powerful learning must involve student and teacher engagement with information for purposes of understanding the information itself, the process by which it has been discovered, and the implications which the information has for application or enhanced understanding of life's significant issues. Kolb described this as the action/reflection cycle (1984). Paulo Friere called this praxis, "the action and reflection of men (sic) upon their world in order to transform it" (1990, p.66). Palmer describes this process as creating a community of truth in which 
conflict enhances understanding and competition diminishes learning. There are a number of areas in which these conditions can be met through collaborative efforts to enhance student learning.

Successful collaborations around the country demonstrate that dedicated faculties, working alongside student affairs professionals, can improve learning in many different ways. "Powerful Partnerships," a report prepared by the National Association of Student Personnel Administrators, the American Association of Higher Education, and the American College Personnel Association, documents many such collaborations; it is available on the Web at http://www.naspa.org and shows how faculty and student affairs are cooperating to create optimal conditions for learning. If you are looking for welldocumented success stories to emulate, you will find many in the seven areas described briefly below:

\section{Service Learning}

More than simply community service, service learning involves providing students with opportunities to offer service to others while simultaneously increasing their awareness of the underlying social, economic, and political conditions which create the need for service learning. Service learning is very effective when academic and student affairs faculty collaborate in creation of syllabi and facilitation of seminars which involve discussions of both impersonal and personal knowledge (Galligan, 1995). Service learning programs provide ideal opportunities for ethics education as well because of the dilemmas students face while providing service to persons whose life circumstances are typically quite different from their own (Saltmarsh, 1997).

\section{Learning Communities}

Learning communities have existed in residence halls since the founding of Oxford and Cambridge Universities. They began to gain popularity in the U.S. in the 1960s in response to student demands for learning which was relevant to their lives. The Intentional Democratic Community concept, originated by Burns Crookston, taught students the theory and practice of democracy in a residential environment. Some learning communities are focused around specific themes such as "Reflections and Connections: Self, Nature and the Environmental Crisis," "How Do You Know: an Inquiry into the Ways of Knowing with an Emphasis on Science," or "Self-Construction: Personal Identity in American Society." St. Lawrence University created these themes as part of its freshman year program. All students in each residential complex take a common course, taught by two or more faculty. Each course has extensive writing and speaking or performance requirements. Residential life staff are encouraged to sit in on the course and participate in out-of-class discussions. Non-residential learning communities are also being developed around the country, in which students use group project and problem solving methods. Although they lack a residential connection, students develop a community. In creating learning communities, student affairs staff may or may not be academic specialists. Yet as process specialists, they apply 
knowledge of group dynamics to draw students into the subject matter and the meaning it holds for them. They also serve as consultants to faculty in group dynamics and design of experiential education.

\section{Extended Orientation Courses}

These courses are often referred to as "University 101" after the first course of this type, instituted at the University of South Carolina under the leadership of John Gardner. Over the course of a semester, students learn study skills, improve writing, researching, and word processing skills, learn to set personal and professional life goals, and begin to plan careers. In addition, topics such as management of personal health, living, and learning in a culturally diverse community separating from parents, managing family responsibilities, conflict management, assertive communication, and stress management are also addressed. Each of these topics can be addressed both intellectually and experientially to maximize student learning and the application of new knowledge for problem solving. Models for these programs vary according to type of institution, demographics of the student body, and sources of institutional support. In any form, they demonstrate the value of integrating academic and experiential learning.

\section{Coordinated Programs}

Coordinated programs can be created on a small scale between one faculty member and one student affairs staff member, or they can involve the major components of a general education curriculum and the creation of a "paracurriculum" in experiential education that is organized and presented by the student affairs staff. In its simplest form, an academic faculty member discusses the syllabus for a specific course, typically in the social sciences or humanities. The student affairs staff member discusses the syllabus and generates co-curricular programs that provide experiential learning opportunities for students in the course. An anthropology teacher and a student affairs professional could generate a simple example. Students who study the processes of norm creation, group boundary development and the use of artifacts and idioms within cultural groups could be required to observe at least two different student groups in public settings and observe their use of space, artifacts, behavior, and language. Each student could write a paper comparing his or her observations to categories of culture formation discussed in class. The papers could also address students' personal reactions to the groups, their choice of whether or not to participate in those groups and so forth. A class discussion of findings would be co-facilitated by the professor and the student affairs professional, with the professor focusing on conceptual material and local applications and the student affairs professional focusing on student reactions, role of culture in formation of self in college and personal introspection. This type of coordination on a large scale requires more effort. It might also require systematic development of both interpersonal and critical thinking skills over an entire group of courses or general education curriculum. 
Many courses in the arts and sciences arouse controversy because various ethnic and cultural groups have challenged traditional course content. These courses may address topics on which the facts are in dispute. Or the interpretation of facts may vary widely and be closely tied to perspectives of ethnicity, history, gender, class, or sexual orientation. In some cases, particularly literature courses, the controversy extends to the choice of materials to be studied. In these types of courses, learning opportunities can easily be lost because the faculty member is not trained in handling conflict. Students learn to be quiet, or to attack each other, but there is little opportunity to listen respectfully, attempt to understand, and learn to tolerate disagreement. Managing conflict-ridden group conversations is a specialty of many student affairs professionals, one that is well suited to these types of courses. Student affairs staff must take the initiative to involve themselves as discussion facilitators, to meet the faculty who teach the courses and to find productive ways to collaborate in creating "communities of truth" in classrooms where conflict or apathy has frozen learning. A second multicultural learning opportunity occurs in courses designed to increase students' knowledge about culture and its relationship to power in society. The University of Massachusetts at Amherst offers "Social Justice Education" (Adams, Bell and Griffin, 1997) in a variety of courses which explore racism, sexism, homophobia, and the prejudices and oppressions associated with class, disability and age. Many colleges and universities include these discussions in extended orientation courses, often using a very practical "how to get along on campus" approach. These courses would benefit from the addition of historical, anthropological and sociological information to supplement their pragmatic approach.

\section{Leadership Education}

Leadership, as a multidisciplinary pursuit, represents another exceptional opportunity for collaboration. Students need behavioral skills such as running meetings, managing conflict, setting goals and public speaking. They also need a range of operational skills including information on managing money, making contracts, marketing and public relations. Finally, students benefit from a broader understanding of the role of leadership in a democracy, effects of leadership style on different groups and tasks, the relationship between leadership and organizational structure, and ethical perspectives on leadership.

\section{Distance Learning}

How do we structure interactions between faculty and students who may be separated by hundreds of miles? Is it possible to create relationships between students taking the same course who may never meet in person? What is the significance of human relationships in the learning process? Can a person experience the deep learning described by Caine and Caine (1997) in a distance learning environment? What role can and should student affairs play? 


\section{Next Thoughts, Next Steps}

By creating a common language in which we can discuss differences, we can begin to examine some of the frightening paradoxes of teaching and learning which have paralyzed our youth and trapped us all in "parallel silos" on campus. We are living in an age of "ill structured problems" (King and Kitchener, 1994) in which most solutions are temporary, problems must be addressed before all relevant knowledge is in hand, and there are few signposts to the "right" answers. We do know that the most powerful educational interventions connect rather than divide us. Connections are interpersonal, intrapersonal, and intrainstitutional. We need to build the mind/body/brain connection into all of our learning processes. We need to teach students to take risks for learning and problem solving. Student affairs professionals must take risks right along with students and faculty. The split in organization of our universities between academic and student affairs does not reflect a similar split in the lives of our students between thinking and feeling. We must collaborate, create new processes for discussing problems and generating solutions, create webs of understanding, respect, and mutual support.

\section{References}

Adams, M., Bell, L., \& Griffin, P. (Eds.). (1997). Teaching for diversity and social justice. New York: Routledge.

Baxter Magolda, M. (1992). Knowing and reasoning in college. San Francisco: JosseyBass.

Belenky, M., Clinchy, B., Goldberger, N., \& Tarule, J. (1986). Women's ways of knowing. New York: Basic Books.

Caine, R., \& Caine, G. (1997). Education at the edge of possibility. Alexandria. VA: Association for Supervision and Curriculum Development.

Crookston, B. (1973). Education for human development. In C. Warnath (Ed.), New

Directions for College Counselors. San Francisco: Jossey-Bass.

Dewey, J. (1933). How we think. Boston: Heath.

Friere, P. (1990). Pedagogy of the oppressed. New York: Continuum Press.

Galligan, A. (1995). Service learning and experiential education. In J. Fried \& Assoc.

Shifting paradigms in student affairs (pp.189-208). Washington, DC: American

College Personnel Association.

King, P., \& Kitchener, K. (1994). Developing reflective judgment. San Francisco: Jossey-Bass.

Kolb, D. (1984). Experiential learning. Prentice Hall: Englewood Cliffs, NJ.

Lloyd-Jones, E., \& Smith, R. (Eds.). (1954). Student personnel work as deeper teaching. New York: Harper \& Brothers.

Marchese, T. (1998). The new conversations about learning. Available at:

http://wwwnewhorizons.org.

Newton, F. (1998). The stressed student-how can we help? About campus. 3 (2), 4-10.

Palmer, P. (1998). The courage to teach. San Francisco: Jossey-Bass. 
Perry W. (1970). Forms of intellectual and ethical development in the college years. New York: Holt, Rinehart \& Winston.

Saltmarsh, J. (1997). Ethics, reflection, purpose and compassion: community service learning. In J. Fried (Ed.). Ethics for today's campus. New Directions in Student Service 77. San Francisco: Jossey-Bass.

Whitehead, A.N. (1929). The aims of education. New York: MacMillan.

Wingspread Group. (1993). An open letter to those concerned about the American future. In An American imperative: Higher expectations for higher education. Racine, Wisc.: The Johnson Foundation 